\title{
BIODIGESTOR SERTANEJO COMO ALTERNATIVA PARA A CONSERVAÇÃO DO SEMIARIDO POTIGUAR
}

\author{
SILVA, J. E. DA ${ }^{1}$ CORREIA, L. A. ${ }^{2}$ \\ Instituto Federal de Educação, Ciência e Tecnologia do Rio Grande do Norte ${ }^{1}$, Universidade Federal do Rio Grande \\ do Norte ${ }^{2}$ \\ ORCID ID: https://orcid.org/0000-0002-5034-638X $^{1}$ \\ edson-jes@hotmail.com ${ }^{1}$ \\ Submetido 15/05/2020 - Aceito 19/08/2020 \\ DOI: $10.15628 /$ holos.2020.10125
}

\section{RESUMO}

No Oeste do Rio Grande do Norte, região semiárida, o Biodigestor Sertanejo emerge, enquanto tecnologia social, como alternativa ao uso do carvão e da lenha, fonte de combustível principal das famílias da zona rural. Assim, diante dos impactos socioambientais positivos do uso desta tecnologia, o objetivo deste trabalho foi apresentar a tecnologia do Biodigestor Sertanejo como alternativa para a conservação do semiárido potiguar. Para isso, realizou revisão da literatura, visita à campo com registro
\end{abstract}

fotográfico e aplicação de formulário de pesquisa com agricultores contemplados com a instalação do Biodigestor Sertanejo. Após a coleta dos dados constatou que o Biodigestor Sertanejo propiciou ganho ambiental ao fornecer uma alternativa ao combustível da Caatinga, como também uma melhoria na qualidade de vida desses moradores, que agora podem cozinhar de forma mais cômoda e econômica.

PALAVRAS-CHAVE: Biodigestor. Semiárido. Desmatamento. Caatinga.

\section{BIODIGESTOR SANTANEJO AS AN ALTERNATIVE FOR THE CONSERVATION OF THE POTIGUAR SEMIARID}

\begin{abstract}
In western Rio Grande do Norte, a semi-arid region, the Biodigestor Sertanejo emerges as a social technology, as an alternative to the use of coal and firewood, the main fuel source for families in the countryside. Thus, in view of the positive socio-environmental impacts of using this technology, the objective of this work was to present the Biodigestor Sertanejo technology as an alternative for the conservation of the semi-arid region of Rio Grande do Norte. For this, it carried out a literature review, a field
\end{abstract}

visit with a photographic record and application of a research form with farmers contemplated with the installation of Biodigestor Sertanejo. After collecting the data, he found that the Biodigestor Sertanejo provided an environmental gain by providing an alternative to Caatinga fuel, as well as an improvement in the quality of life of these residents, who can now cook more comfortably and economically.

KEYWORDS: Biodigester. Semiarid. Deforestation. Caatinga. 


\section{INTRODUÇÃO}

Durante um longo período, os habitantes da zona rural de municípios do semiárido brasileiro possuíam o carvão e a lenha como principais fontes de combustível para cozinhar, porém essas duas fontes além de dificultar a vidas dessas famílias causavam desmatamento do bioma Caatinga, um grave problema ambiental. O problema ainda é pior no caso do carvão, pois na sua fabricação é utilizado a vegetação viva e em poucas áreas os produtores de carvão fazem o devido reflorestamento (Kill et al., 2007). Nesse contexto, e visando a diminuição do impacto ambiental causado pelo desmatamento da Caatinga para uso nas atividades domésticas, surgiram várias tecnologias sociais, dentre as quais destacamos o Biodigestor Sertanejo.

O biodigestor teve sua origem na China e logo após na Índia e que vem sendo implementado em diversos outros países, a exemplo da América Latina e Caribe, conforme Revista Redbiolac que desde 2007 vem propondo projetos e mecanismos para disseminação da tecnologia de biodigestores nessas áreas. No Brasil, estudos ganham espaço no meio científico apontando a potencialidade do biodigestor, sua importância e eficiência principalmente em áreas na zona rural no Nordeste, bem como a importância da tecnologia para o meio ambiente e para a produção de energia alternativa (Vivian et al., 2010; Arruda et al., 2002; Turdera \& Yura, 2006). Diante da relevância do tema, este trabalho aborda o uso do biodigestor e a sua potencialidade, notadamente nas áreas ambiental e social.

O Biodigestor Sertanejo é uma tecnologia social adaptada de um modelo indiano que utiliza materiais de fácil acesso e baixo custo encontrados em lojas de material de construção. Seu processo consiste na transformação do esterco animal em gás metano, altamente inflamável e semelhante ao gás liquefeito de petróleo (GLP) - o gás de cozinha. Tendo em vista a relevância desta tecnologia, e o seu impacto socioambiental, Organizações Não Governamentais (ONG's) tem buscado financiamento para implantação do Biodigestor Sertanejo na região Oeste do Rio Grande do Norte. Dentre os financiadores destacamos a Ajuda da Igreja da Noruega - AIN que viabilizou, em parceria com uma ONG, a implantação de mais de 200 unidade do Biodigestor Sertanejo na região Oeste do Rio Grande do Norte entre os anos de 2011 a 2016.

Assim, diante do movimento de implantação do Biodigestor Sertanejo nas comunidades do Oeste Potiguar e entendendo que o seu uso contribui tanto para melhoria de qualidade de vida dos sertanejos quanto na conservação do semiárido, na medida em que oferta uma fonte alternativa à lenha e ao carvão; o trabalho em tela apresenta o Biodigestor Sertanejo como alternativa para a conservação do semiárido potiguar. Esse trabalho compõe o rol de pesquisas que destacam a relevância socioambiental do uso do biodigestor em ambiente semiárido.

\section{REVISÃO BIBLIOGRÁFICA}

Os biomas brasileiros abrigam uma porção significativa da biodiversidade mundial, constituindo importantes centros de biodiversidade pela combinação de altos níveis de riqueza e endemismo (Aleixo et al., 2010). O Brasil possui seis regiões distintas, chamadas de biomas, são elas: 
Amazônia, Mata Atlântica, Cerrado, Pantanal, os Pampas e a Caatinga. Geralmente, quando se fala em Caatinga as pessoas associam a um ambiente seco, pobre, e de baixa biodiversidade, relacionando a fome e a escassez. Contudo, o Bioma Caatinga é um dos mais ricos e biodiversos, genuinamente brasileiro, não é encontrado em nenhum outro lugar do mundo (Sena, 2011).

O Bioma Caatinga está localizado na Região do Semiárido (Souza, Artigas \& Lima, 2002), e ocorre no clima de mesmo nome. O Semiárido brasileiro abrange os seguintes estados: Ceará, Rio Grande do Norte, Paraíba, Pernambuco, Piauí, Alagoas, Sergipe, Bahia, Maranhão e uma pequena parte de Minas Gerais (Correia et al., 2011). Possui grande influência climática de fenômenos meteorológicos que interferem diretamente no período chuvoso e, consequentemente, na pluviosidade anual da região, esses fenômenos são: La nina, El nino e Dipolo do Atlântico Norte (Correia et al., 2011). A precipitação média anual é de $800 \mathrm{~mm}$ e temperatura média do ar em torno de $26^{\circ} \mathrm{C}$. O clima semiárido por sua vez é predominante do tipo BShw de Köppen, ou seja, quente e seco, motivos pelo qual a Caatinga se apresenta como o principal bioma, já que ela se adapta as condições extremas ali presente (Silveira et al., 2018).

Estudos apontam (Sena, 2011), que dentre todos os biomas brasileiros, a Caatinga é o que mais têm sofrido com modificações ambientais e climáticas, perdendo suas características semiáridas e se tornando áridas, que são aquelas regiões pobres e desérticas (Santos et al., 2013), por isso é tão importante a implementação de políticas públicas que promovam a sua conservação. A preservação da Caatinga deve estar presente na vida dos sertanejos, a Caatinga possui uma grande diversidade de répteis, mamíferos, aves, anfíbios, peixes e abelhas, que estão diminuindo com o desmatamento e por isso que é tão importante a preservação desse bioma (Alves, Araújo, \& Nascimento, 2008).

É possível encontrar o bioma Caatinga em 10 estados brasileiros, sendo em sua grande maioria estados do Nordeste (Giulietti et al., 2004) O semiárido é habitado em grande parte por agricultores e seus familiares que têm sua renda proveniente da agricultura de subsistência e da criação de animais. Muitos utilizando a forma agroecológica em consonância com o meio ambiente, contribuindo intuitivamente com a preservação da natureza. Contudo, outra grande parcela ainda usa formas convencionais que afetam negativamente o meio ambiente (Sena, 2011). Pensando nesse problema, nos últimos anos órgãos públicos e ONGs vem desenvolvendo projetos no sentido de diminuir os danos ambientais e tentar transmitir uma ideia mais realista a respeito da Caatinga e de sua importância. Um desses projetos possibilitou a implantação do biodigestor sertanejo, que vem sendo cada vez mais utilizado no Nordeste.

O biodigestor é oriundo da China, um primeiro modelo foi desenvolvido em 1936, os indianos também desenvolveram outro modelo, dando início ao processo de biodigestão de matéria orgânica, resultando no gás metano e em resíduos decompostos, ricos em nutrientes utilizados para fertilizar solos (Junqueira, 2014). Com o passar dos anos, outros modelos foram sendo desenvolvidos, e funcionam até os dias de hoje, são bastantes utilizados em diversas propriedades rurais em todo o mundo. No Brasil, essa tecnologia foi implantada nos anos 70, pela Superintendência de Desenvolvimento do Nordeste - SUDENE (Junqueira, 2014). E em 2008 começaram a implantação do biodigestor Sertanejo na região Nordeste nos estados da Paraíba, Pernambuco e Rio Grande do Norte e após os resultados esse projeto foi expandido para outras 
regiões, contemplando os estados de Rio Grande do Sul, Santa Catarina, Goiás, Minas Gerais, Bahia e Pernambuco, com um projeto financiado pela Caixa Econômica Federal.

\section{MATERIAIS E MÉTODOS}

O trabalho em tela é fruto de uma pesquisa aplicada de caráter exploratória (Prodanov \& Freitas, 2013). Assim, com vistas a apresentação do Biodigestor Sertanejo como alternativa para a conservação do semiárido potiguar, foi realizada Pesquisa bibliográfica para revisão da literatura, buscando evidenciar a relevância do Bioma Caatinga e da conservação do Semiárido. Para geração dos resultados foi realizada visita à campo com registro fotográfico e aplicação de formulário de pesquisa à 21 agricultores, ou seja, uma amostragem de $20 \%$ dos contemplados com a instalação do Biodigestor Sertanejo. Inicialmente, a previsão era de entrevistar $100 \%$ das famílias através de uma visita in loco, mas isso não foi possível devido a distância entre as propriedades. Sendo assim, optou se por um questionário no Google, e com isso a amostra ficou diretamente condicionada ao acesso à internet. Logo, o instrumento de pesquisa foi enviado apenas para as famílias que possuem acesso à internet. Eles foram inquiridos quanto ao tempo de uso da tecnologia, a fonte de energia que utilizavam antes da implantação do biodigestor, a quantidade de gás de cozinha utilizado antes e após a implantação do biodigestor, a quantidade de carvão e lenha utilizado antes da implantação do biodigestor, se ainda utiliza a caatinga como fonte de combustível, bem como sobre a avalição deles em relação ao Biodigestor Sertanejo.

\section{RESULTADOS E DISCUSSÕES}

O Biodigestor Sertanejo é uma tecnologia social adaptada de um modelo indiano e de baixo custo construtivo, que tem como matéria prima o esterco animal. Ele é formado por quatro caixas: caixa de entrada, de fermentação, tanque de armazenamento de gás e a caixa de saída (Figura 1).

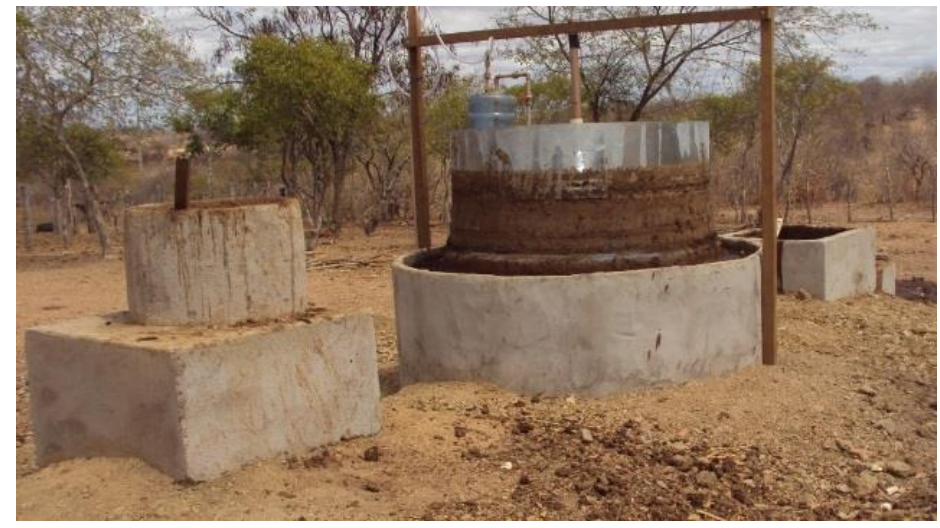

Figura 1: Biodigestor Sertanejo construído no assentamento São José município de Caraúbas RN. Fonte: Acervo do autor, 2020

A Figura 1 apresenta a estrutura do Biodigestor Sertanejo e suas 4 caixas. A Caixa de entrada é onde o esterco é colocado e canalizado para a caixa de fermentação; nesta o esterco é armazenado e acontece a fermentação. Na sequência tem-se o Tanque de armazenamento de Gás, essa caixa diferente das outras não é feita de alvenaria e sim de fibra de vidro, é nela que o gás é armazenado e canalizado para o fogão. E por fim temos a caixa de Saída de onde sai o esterco já sem o gás para 
ser utilizado na agricultura como adubo natural. A caixa de saída é dividida ao meio, de um lado fica a parte solida e do outro lado é filtrado por uma tela e passa a parte liquida também chamada de biofertilizante que é utilizado como adubo natural foliar nas plantas (Gaspar, 2003).

A implantação do Biodigestor Sertanejo na região Oeste do Rio Grande do Norte (Figura 2), foi iniciada no ano de 2011 com financiamento da Ajuda da Igreja da Noruega - AIN que, em parceria com a ONG, realizou a implantação de 200 Biodigestores Sertanejos construídos do ano de 2011 até de 2016, período de vigência do projeto.

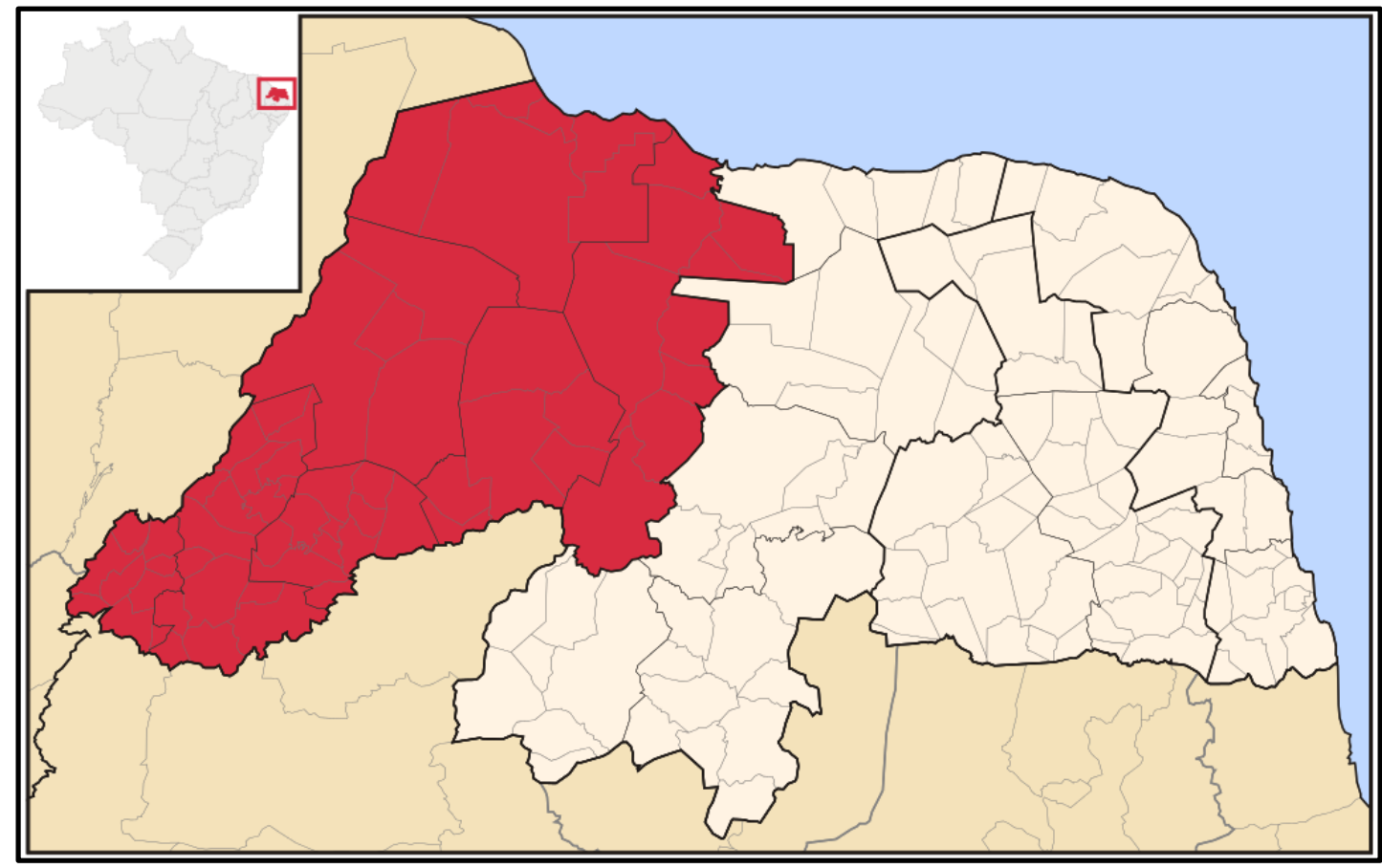

Figura 2: Microrregiões do Rio Grande do Norte.

Fonte: De "Map locator of Rio Grande do Norte's Oeste Potiguar mesoregion" de R. L. Abreu, 2016, Wikimedia Commons.

Durante a implantação dos Biodigestores, a Ajuda da Igreja da Noruega - AIN entrou com o recurso, a ONG contratava pessoal para mobilização das famílias e implementação da tecnologia social, as famílias eram escolhidas em reuniões comunitárias na própria comunidade com os agricultores e representações sociais como sindicatos. Nessas reuniões era apresentado o biodigestor sertanejo e as famílias interessadas participavam de intercâmbios para conhecerem outras famílias que já utilizavam, para poder receber o biodigestor as famílias tinham que ser carentes e beneficiárias de programas sociais do governo federal.

A construção em si, era feita em parceria com a família, que em pouco tempo já possui todo o domínio da tecnologia e de forma simples consegue manusear e fazer a manutenção necessária para o melhor funcionamento do Biodigestor. Através de um acompanhamento técnico junto com a família levando em conta os princípios da agroecologia, e o respeito aos valores e conhecimento locais. Sobre isso, Paulo Freire nos explica que "toda invasão sugere, obviamente, um sujeito que invade. (...) superpondo aos indivíduos seu sistema de valores" (Freire, 1985, p. 26). E não era esse o objetivo da instalação dos Biodigestores, mas sim a apropriação da tecnologia pelas famílias para melhoria da sua qualidade de vida e uma convivência mais sustentável com o meio ambiente. 
Diante da experiência do projeto, e reconhecendo a relevância do Biodigestor para conservação do Semiárido, entrevistamos 21 agricultores contemplados com a tecnologia. $\mathrm{Na}$ sequência estão as figuras com os resultados da pesquisa. A figura 3 apresenta a o município de residência dos entrevistados.

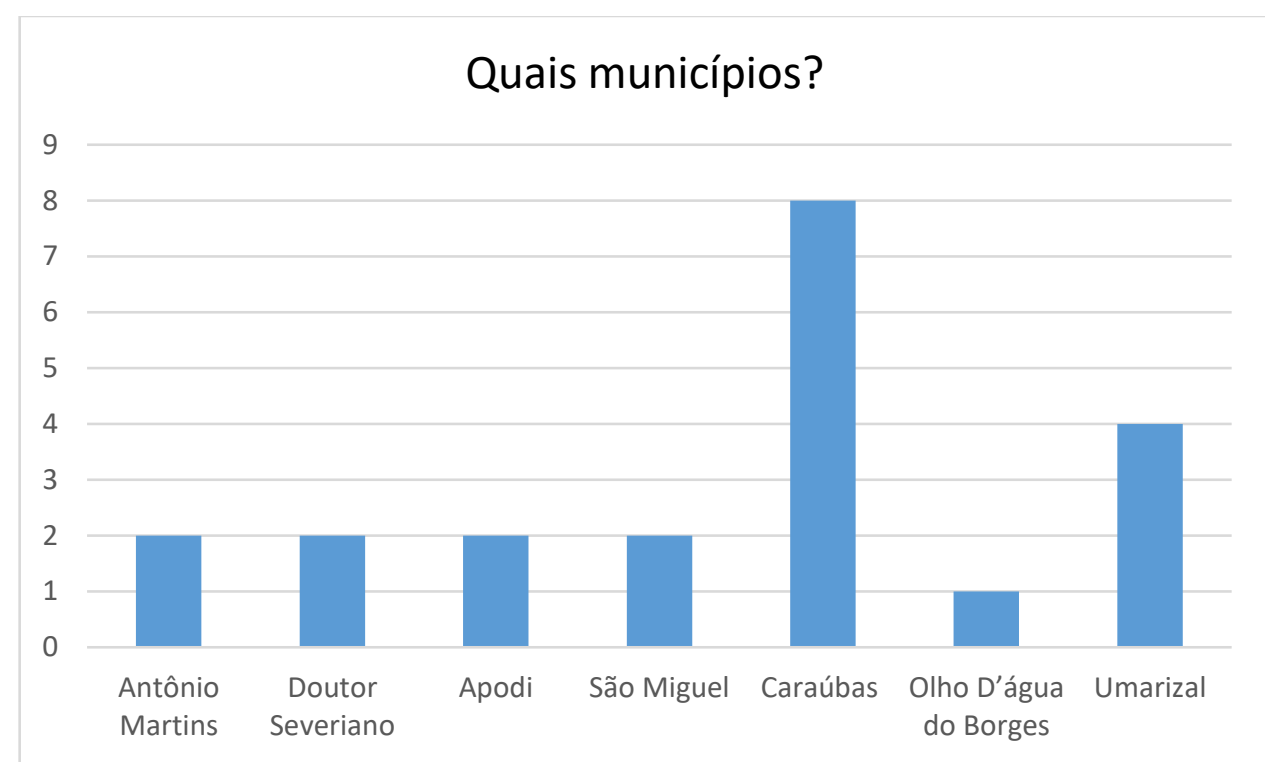

Figura 3: Municípios dos participantes.

Fonte: Pesquisa de campo, 2020

Conforme anunciado anteriormente, todos os entrevistados residem em municípios do Oeste Potiguar, onde foram implantados biodigestores, e estão distribuídos da seguinte forma: dois nas seguintes cidades: Antônio Martins, Doutor Severiano, Apodi e São Miguel. Oito em Caraúbas, um e Olho D'água dos Borges e quatro em Umarizal.

Os entrevistados foram inquiridos sobre o tempo de uso do Biodigestor pela família. A Figura 4 apresenta os resultados:

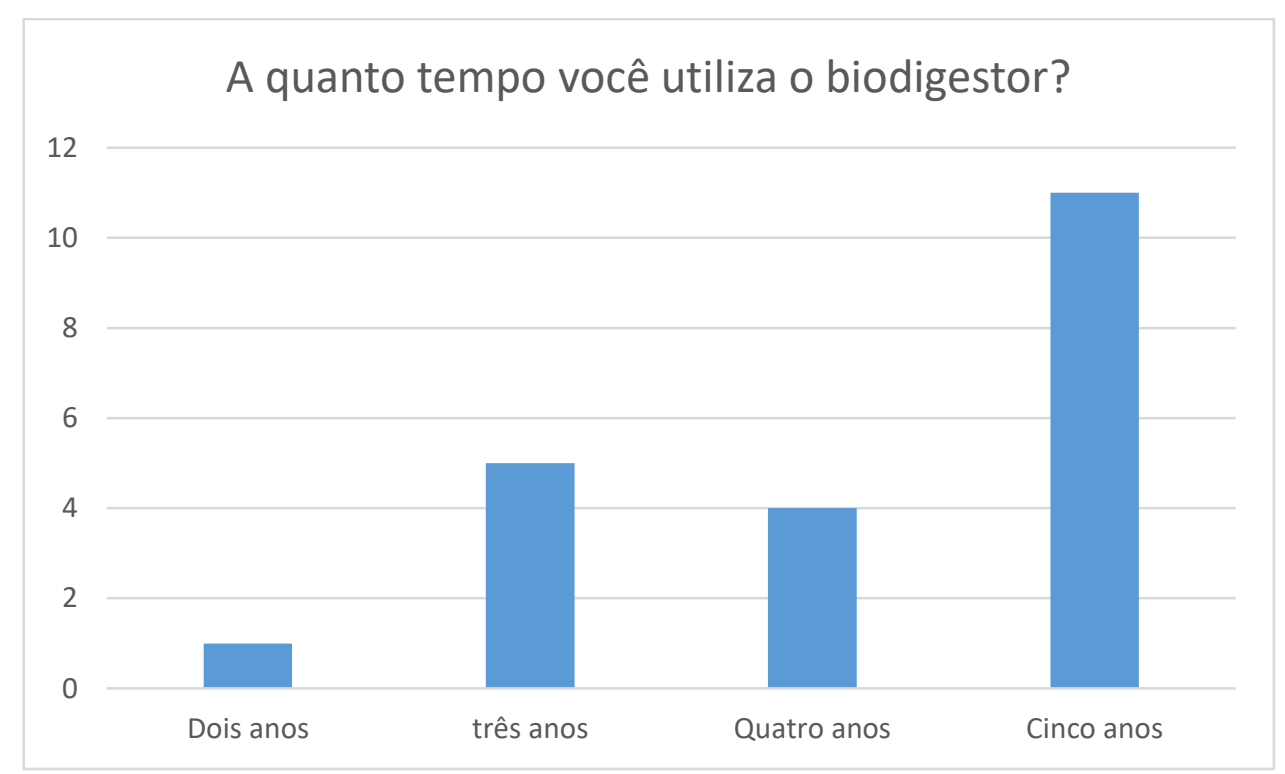

Figura 4: Tempo em que os participantes já utilizam o biodigestor.

Fonte: Pesquisa de campo, 2020 
Os resultados apresentados na Figura 4, mostram que um dos entrevistados utilizava o biodigestor a dois anos, cinco deles a três anos, quatro entrevistados a quatro anos e onze a cinco anos. Ou seja, todos os participantes já utilizam o biodigestor a mais de dois anos, tempo suficiente para avaliar a eficiência da tecnologia social.

Questionamos também quais fontes de energia eram utilizadas pelas famílias antes da construção do biodigestor. O resultado consta na figura 5:

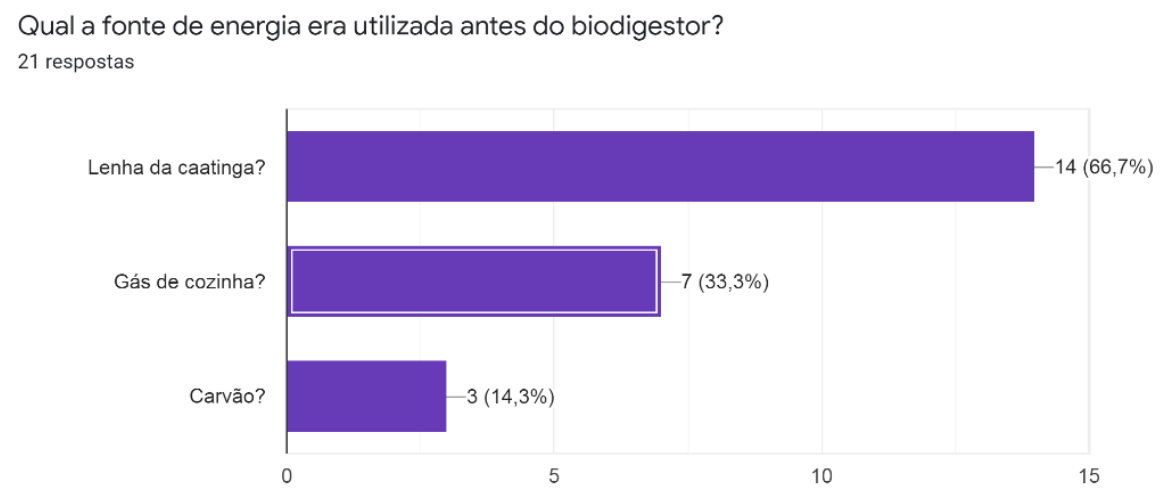

Figura 5: Fonte de energia utilizada pelos participantes, antes da implantação do biodigestor. Fonte: Pesquisa de campo, 2020

Podemos observar na figura 5 , que antes da implantação do biodigestor, $67,6 \%$ das pessoas entrevistadas ( 14 pessoas) utilizavam a lenha oriunda da Caatinga e outros 14,3\% ( 3 pessoas) faziam uso do carvão. Ou seja 81,9\%, 17 pessoas das 21 entrevistadas, dependiam da exploração da vegetação para cozinhar, o que era um fato preocupante, levando em consideração a degradação ambiental no Semiárido e as mudanças climáticas já existentes.

De acordo com os dados obtidos, constata-se a partir do uso do Biodigestor Sertanejo, uma redução considerável no uso da lenha e do carvão, conforme a figura 6 , que revela quantos entrevistados ainda usam a lenha para cozinhar após a implantação do Biodigestor.

Você ainda utiliza lenha ou carvão? 21 respostas

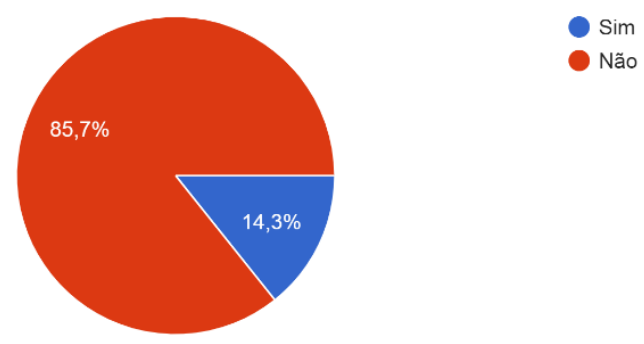

Figura 6: porcentagem dos participantes que utilizam ou não a lenha ou carvão. Fonte: Pesquisa de campo, 2020

Após a implantação do biodigestor houve uma diminuição considerável na exploração da vegetação nativa, observando os valores encontrados na Figura 6, podemos notar uma severa 
redução no uso do carvão e da lenha, considerando-se que antes da tecnologia $81,9 \%$ dos entrevistados (18 pessoas) utilizavam lenha ou carvão, após a implantação esse número caiu para significativos 14,7\% ( 3 pessoas) ou seja 85,7\%, 17 das 21 pessoas entrevistadas, deixaram de explorar esse recurso escasso no semiárido.

A Figura 7, apresenta o tempo de uso do biodigestor de cada família entrevistada.

\section{Avaliação do Biodigestor Sertanejo}

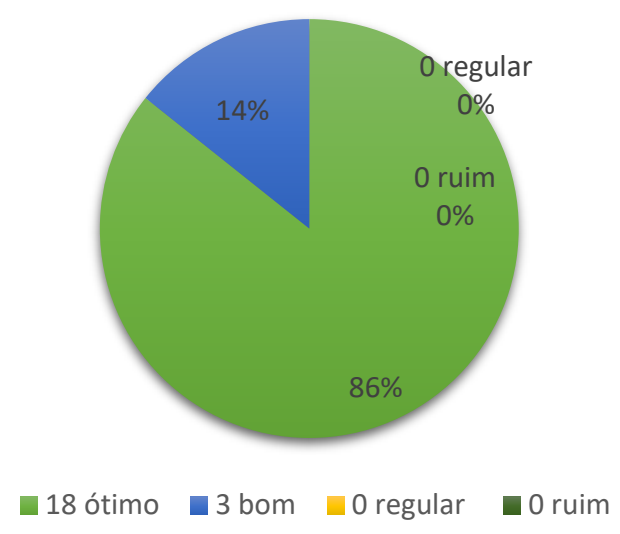

Figura 7: Avaliação do biodigestor. Fonte: Pesquisa de campo, 2020

É importante ressaltar a tamanha aceitação das famílias, podemos ver com clareza na Figura 7 , que $90,5 \%$ dos entrevistados (19 pessoas) consideram o biodigestor ótimo e os outros $9,5 \%$ ( 2 pessoas) como bom, destacando assim que a tecnologia, além de conservar a natureza, promove a redução dos gastos, e por ser de fácil manuseio é bastante aceitável pelas famílias. Quando o processo de instalação foi iniciado várias famílias tinham preconceito com a tecnologia, pois o gás seria gerado através do esterco, e alguns temiam que fosse poluído, mas com intercambio de conhecimento, viram alguns em funcionamento e esse preconceito foi diminuindo, e o Biodigestor começou a ser aceito pelas famílias agricultoras.

Os dados mostram que todos os participantes já utilizam o biodigestor há dois ou mais anos, tempo suficiente para nos ajudar a compreender o seu potencial. Com isso observamos que a tecnologia social do Biodigestor sertanejo propicia ganhos nas mais variadas áreas. Na área ambiental destacamos o impacto positivo do não lançamento do metano na atmosfera, tendo em vista que ele se transforma em gás carbônico no processo de queima, o qual é 23 vezes menos poluente que o metano (Ferreira, 2011). Além disso, o Biodigestor sertanejo propicia uma significativa economia na compra do gás GLT (gás de cozinha), reduzindo o gasto médio das famílias que o utilizam. Além de toda questão ambiental e econômica, destacamos a questão de gênero. Uma vez que, via de regra, são as mulheres que preparam a comida da família, tendo elas a missão de procurar lenha na mata, são as mesmas quem primeiro se interessam pela construção do biodigestor e após a construção são as mulheres que fazem todo o manuseio da tecnologia (Gaspar, 2003). 


\section{CONSIDERAÇÕES FINAIS}

Os biodigestores implementados no Oeste potiguar trouxeram inúmeros resultados: entre eles ganhos ambientais como a diminuição significativa no desmatamento da caatinga, considerando que várias famílias utilizavam a lenha como combustível para fogão. Com a utilização do biodigestor houve uma diminuição significativa no uso da lenha e do carvão, pois, os familiares deixaram de utilizá-los e começaram a fazer uso do gás do biodigestor. Outro fator positivo foi de as famílias não terem mais contato com a fumaça e a fuligem da lenha queimada no fogão, que antes era um problema, podendo até mesmo causar alguma doença respiratória. Percebemos que o biodigestor não é apenas uma forma de diminuir impactos ambientais, como tecnologia social, ela representa uma forma de melhoria de vida para todos aqueles que antes não podiam cozinhar de forma mais cômoda.

A partir da pesquisa realizada, percebermos a importância da implantação de tecnologias sociais em comunidades, principalmente nas mais carentes. Tecnologias como a do biodigestor promove ganhos, não somente para as pessoas contempladas, como também para o meio ambiente. Foi motivo de grande satisfação poder fazer essa pesquisa e perceber que de forma simple essa tecnologia tem sido útil para famílias sertanejas e que o biodigestor Sertanejo está diminuindo significativamente a devastação do bioma caatinga e conservando a saúde dessas pessoas.

\section{REFEREÊNCIAS}

Abreu, R. L. de (2016, abril 27). Map locator of Rio Grande do Norte's Oeste Potiguar mesoregion [Wikimedia Commons]. Recuperado de: https://commons.wikimedia.org/w/index.php?curid=1370394

Aleixo, A. L. P., Albernaz, A. L. K. M., Grelle, C. E. V., Vale, M. M., \& RangeL, T. F. (2010). Mudanças climáticas e a biodiversidade dos biomas brasileiros: passado, presente e futuro. Natureza \& Conservação, 8(2), 194-196.

Alves, J.J.A., Araújo, M.A. \& Nascimento, S.S. (2008). Degradação da caatinga: uma investigação ecogeográfica. Caminhos de Geografia, 9(27), 143-155.

Arruda, M. H., Amaral, L. D. P., Pires, O. P. \& Barufi, C. R. (2002). Dimensionamento de biodigestor para geração de energia alternativa. Revista científica eletrônica de agronomia, 1(2), 1-8.

Correia, R. C., Kiill, L. H. P., Moura, M. S. B., Cunha, T. J. F., Jesus Júnior, L. A., \& Araújo, J. L. P. (2011). A região semiárida brasileira. In T. V. VOLTOLINI (Ed.), Produção de caprinos e ovinos no Semiárido. (Cap. 1, pp. 21-48). Petrolina: Embrapa Semiárido.

Ferreira, R.C.S. (2011). Emissão de Gás Metano por Bovinos de leite em exposições/feiras. (Trabalho de conclusão de curso). Universidade Federal do Paraná, Curitiba, PR, Brasil.

Freire, P. (1985). Extensão ou comunicação? (8 ed.). Rio de Janeiro: Paz e Terra.

Giulietti, A. M., Bocage Neta, A. L., Castro, A. A. J. F., Gamarra-Rojas, C. F. L., Sampaio, E. V. S. B., Virgínio, J. F., ... Harley, R. M. (2004). Diagnóstico da vegetação nativa do bioma Caatinga. Biodiversidade da Caatinga: áreas e ações prioritárias para a conservação. 
Gaspar, R.M.B.L. (2003). Utilização de biodigestores em pequenas e médias propriedades rurais, com ênfase na agregação de valor: um estudo de caso na Região de Toledo-PR (Dissertação de mestrado). Universidade Federal de Santa Catarina. Florianópolis, SC, Brasil.

Junqueira, S. L. C. D. (2014). Geração de energia através de biogás proveniente de esterco bovino: estudo de caso na Fazenda Aterrado (Trabalho de conclusão de curso). Universidade do Rio Janeiro, Rio de Janeiro, RJ, Brasil.

Kiill, L. H. P. (2007). Preservação e uso da caatinga. Área de Informação da Sede-Col Criar Plantar ABC 500P/500R Saber (INFOTECA-E).

Mapasblog. Mapas do Rio Grande do Norte. Recuperado de: https://mapasblog.blogspot.com/2011/12/mapas-do-rio-grande-do-norte.html.

Prodanov, C. C., \& Freitas, E. C. de. (2013). Metodologia do trabalho científico: métodos e técnica da pesquisa e do trabalho acadêmico (2 ed.). Nova Hamburgo: Feevale.

Redbiolac. (2020). Recuperado de: http://redbiolac.org/pt-br/.

Santos, H. G., Jacomine, P. K. T., Anjos, L. H. C., Oliveira, V. A., Lumbreras, J. F., Coelho, M. R., ... Oliveira, J. B. de. (2013). Sistema brasileiro de classificação de solos. (3 ed.) Rio de Janeiro: Embrapa.

SENA; L.M.M. de. Conheça e conserve a caatinga - O bioma caatinga. Fortaleza: Associação Caatinga.

Silveira, H.L.F. DA., Galvao, L.S., Sanches, I.D., Sá, I.B., \& Taura, T.A. (2018). Use of MSI/Sentinel-2 and airborne LiDAR data for mapping vegetation and studying the relationships with soil attributes in the Brazilian semi-arid region. International Journal of Applied Earth Observation and Geoinformation, 73, 179-190.

Souza, B. I. de., Artigas, R. C., \& Lima, E. R. V. de. (2015). CAATINGA E DESERTIFICAÇÃO. Mercator (Fortaleza), 14(1), 131-150. https://doi.org/10.4215/RM2015.1401.0009

Turdera, M. V., \& Yura, D. (2006). Estudo da viabilidade de um biodigestor no município de dourados. Proceedings of the 6. Encontro de Energia no Meio Rural. Campinas.

Vivan, M., Kunz, A., Stolberg, J., Perdomo, C., \& Techio, V. H. (2010). Eficiência da interação biodigestor e lagoas de estabilização na remoção de poluentes em dejetos de suínos. Revista Brasileira de Engenharia Agrícola e Ambiental, 14(3), 320-325.

\section{COMO CITAR ESTE ARTIGO:}

Silva, J. E. da, Correia, L. A. (2020). Biodigestor Sertanejo como alternativa para a conservação do semiárido Potiguar. Holos. 36(6), 1-11.

\section{SOBRE OS AUTORES}

\section{J. E. DA SILVA}

Técnico em agropecuária pelo Instituto federal do Pernambuco, licenciado em Educação física pela Universidade Federal do Rio Grande do Norte e Especialista em Educação ambiental e geografia do semiárido pelo Instituto federal do Rio Grande do Norte.

E-mail: edson-jes@hotmail.com

ORCID ID: https://orcid.org/0000-0002-5034-638X 


\section{A. CORREIA}

Doutoranda no Programa de Pós Graduação em Geografia da Universidade Federal do Rio Grande do Norte - UFRN. Mestre em Desenvolvimento e Meio Ambiente pela mesma Universidade (2016). Licenciada em Geografia pelo Instituto Federal de Educação, Ciência e Tecnologia do Rio Grande do Norte - IFRN (2013). Pesquisadora no Núcleo de Pesquisas e Estudos Geográficos - NUPEG/ IFRN. Atua nos seguintes temas: Cidades Saudáveis, Planejamento e Gestão do Território, Geografia e Meio ambiente, Saneamento Básico, Vulnerabilidade Socioambiental, Metodologia do trabalho científico.

E-mail: lais2004@gmail.com

ORCID ID: https://orcid.org/0000-0001-9446-3003

Editor(a) Responsável: Francinaide de Lima Silva Nascimento Pareceristas Ad Hoc: George Simonelli, Rodrigo Silva e Albino Nunes

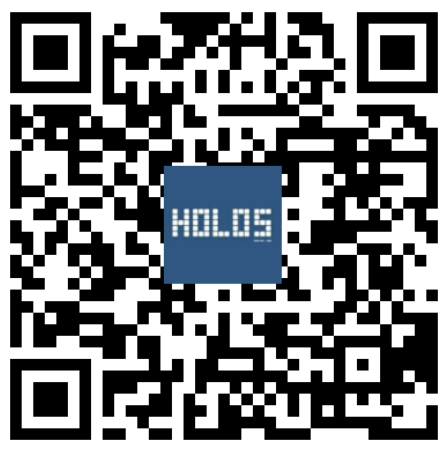

